Research Article

\title{
Investigations on the Mechanical Properties of Natural Fiber Granulated Composite Using Hybrid Additive Manufacturing: A Novel Approach
}

\author{
R. Anandkumar $(\mathbb{D}$, , S. Ramesh Babu, and Ravishankar Sathyamurthy \\ Department of Mechanical Engineering, KPR Institute of Engineering and Technology, Coimbatore 641407, India \\ Correspondence should be addressed to R. Anandkumar; ranandkumarmech@gmail.com
}

Received 22 February 2021; Accepted 22 April 2021; Published 3 May 2021

Academic Editor: H. P. S. Abdul Khalil

Copyright (C) 2021 R. Anandkumar et al. This is an open access article distributed under the Creative Commons Attribution License, which permits unrestricted use, distribution, and reproduction in any medium, provided the original work is properly cited.

\begin{abstract}
In this work, experiments on mechanical properties such as tensile, flexural, effects, and stiffness testing are performed on natural fiber granulated composites (NFGC) manufactured using a hybrid additive manufacturing technique. The natural fiber granulated composites are prepared using the powdered form of sugarcane, jute, ramie, banana, pineapple fiber, and seashell powder with a volume fraction of 0.8 . In the hybrid additive manufacturing technique, the fused deposited modeling (FDM) machine is modified by combining with the shape deposition modeling (SDM) to print the specimens layer by layer, and the influence of the number of layers on the mechanical properties is analyzed. The results concluded that increasing the number of layers from 6 to $12 \mathrm{improved}$ the mechanical properties such as tensile strength, flexural strength, impact strength, and hardness values by 40.84, 50.04, 21.55, and $20.55 \%$, respectively. Further, a novel technique can be utilized for developing the composites in replacement with conventional methods.
\end{abstract}

\section{Introduction}

In the present scenario, industries are mainly focusing on the concept of sustainable manufacturing by reducing the usage of nonrenewable resources and adopting eco-friendly processes on materials by recycling or reuse of waste. For this purpose, composite materials are prepared, and extensive research works are carried out by researchers in several parts of the world [1]. Among those, polymer and natural fiberbased composites were identified as excellent materials due to their desirable properties such as reusability, recyclability, long-term stability, and abundant availability at a reasonable cost. Further, the natural fiber-reinforced composites (NFRCs) are utilized for the products used in biomedical, automotive, packing, and constructional applications [2]. Natural fiber production also consumes about 5.72 times lesser energy than glass fiber production [3]. Even though the natural fiber consists of its own merits, several intensive factors affect the material properties, such as high moisture absorption, poor wettability, significant variation in fiber characteristics, and low thermal stability.

NFRCs were prepared with various compositions and different manufacturing techniques were used to overcome these limitations. Prasad et al. [4] analyzed the influence of jowar, sisal, and bamboo fiber on the mechanical properties of the NFRCs with a volume fraction of 0.4. They concluded that jowar fiber composite has high strength and rigidity, and it is suitable for low-weight applications compared with others. Bordos et al. [5] used the compression molding technique and developed the flax fiber composites, which enhanced the tensile properties of biopolymers, which had characteristics similar to glass fiber composites. Alavudeen et al. [6] analyzed and compared the performance of banana/ kenaf-reinforced composites with plain and twill-type orientation. They reported that plain oriented composites improve mechanical strength by $10 \%$ compared with others. The mechanical properties of banana fiber composites were also enhanced by adding sisal fiber up to the volume fraction 
of 0.5 [7]. Silva et al. [8] reported that the composite materials with $30 \%$ of sisal and banana natural fibers enhanced the interfacial bonding. Researchers also reported that if the fiber content was $<40 \%$ and fiber length ranges from 0.1 to $1 \mathrm{~mm}$, the injection molding technique produces better composites. If the fiber content exceeds $>40 \%$ and the fiber length was more than $10 \mathrm{~mm}$, compression molding was suggested [9-11]. The powder-based natural composites are also developed by using sheesham wood and rice husk powder. It is concluded that the mechanical properties are decreased with increasing fiber content beyond $20 \mathrm{wt}$. \% [12]. The alkali treatment of natural fiber that provided roughness removed a certain amount of lignin and enhanced natural fiber adhesiveness [13, 14]. Even though enormous works are carried out in this field, the NFRCs have lower mechanical and functional performance due to porosity formulation caused by poor interaction or bonding between fiber and matrix. The researchers overcome these limitations by incorporating additive manufacturing (AM) techniques for fabricating the composites.

Additive manufacturing (AM) played a major role in the rapid growth of the industries in the product earlier. AM has many variants based on the materials that could be printed. Among different variants of AM, the economically viable variant is fused deposition modeling (FDM), which is categorized under extrusion type [15-18]. The FDM technology is used for printing plastics, nylons, and composite materials. The cheapest technology always has potential growth, as it attracts the manufacturing industries faster. So the rate of growth is higher for this FDM variant. FDM method has undergone many modifications, among which the filament has shown considerable growth.

Matsuzaki et al. [19] used the FDM technique for developing the PLA matrix composites reinforced by twisted yarns of natural jute fibers, which enhanced the tensile strength and tensile modulus by $134 \%$ and $157 \%$, respectively. Hinchcliffe et al. [20] reported that the tensile strength, stiffness, and flexural strength of jute and flax fiberreinforced hybrid composites were improved by $116 \%, 14 \%$, and $10 \%$ when incorporating the FDM process. Le Duigou et al. [21] incorporated the recycled wood fiber-based biocomposites formulated using the FDM technique and reported that the porosity formulation is around $20 \%$, weakening the mechanical properties. Le Duigou et al. [22] reviewed various $3 \mathrm{D}$ printing techniques and concluded that hybridization of AM technologies could improve the printing quality of composites with a higher concentration of natural fibers [22].

The biomaterial-based filaments have started hitting the market with one of its kind, which is the wood-filled composite filament developed by researchers [23]. Calverton [24] introduced nanocomposite-based filament with graphene that is being used in batteries. 3D Fuel and Algix companies developed algae-based composite filament with PLA [25]. To serve the aerospace industries, several companies are developing metal-infused composite materials [26]. Eastman and ColorFabb companies developed the filament for the next generation, which is made out of carbon fiber and brass [27]. Graphene 3D company developed magnetic filaments and introduced them in the market, capable of attracting magnetic material after printing [28]. 3DomFuel Company has introduced different types of unique filaments to the market since 2016, which are plastic infused with hemp, coffee, and beer [29]. FIBERLAB Company unveils the flexible and temperature fluctuation-resistant filament, capable of withstanding temperature variation between $70^{\circ} \mathrm{C}$ and $-40^{\circ} \mathrm{C}$ [30]. The composite filament growth provides a new path to print directly from the electronic components like a resonator [31].

The remarkable modifications made on the printer head are discussed below. Matsuzaki et al. [32] developed a printer that PLA was drawn from the top path and jute was added through the side filament path. As a result, continuous filament PLA with jute infused was derived out, and its properties were tested [32]. Owen et al. [33] developed a printer to print the ceramic slurry with a modified printing head from the existing delta-type FDM machine. Kumar et al. [46] optimized the process parameters involved in the preparation of kenaf fiber through the design of the experiment. Results revealed that the optimum process parameters such as $\mathrm{NaOH}$ concentration, process temperature, process time, and fiber-to-solution weight ratio were found as $6 \%, 30^{\circ} \mathrm{C}, 8$ hours, and $1: 15$, respectively, to attain a maximum tensile strength of 58.16 MPa. Malingam et al. [47] studied the static and dynamical mechanical properties of kenaf fiber-reinforced hybrid composite. Merizgui et al. [48] studied the effect of iron oxide particles with kenaf fiber-reinforced composite. In addition to iron oxide, MWCNT was added to the composite. Nematollahi et al. [49] studied the behavior of kenaf fiber-reinforced polypropylene composite prepared through extruded injection molding. Mechanical and morphological behavior on fiber content reinforced with low-density polyethylene using rotational molding was experimentally investigated by Abilesh and Singaravelan [50].

From the above literature, it is identified that the incorporation of additive manufacturing enhances the properties of NFRCs. There are several problems such as void formation, nozzle blockage, fiber agglomeration, and distribution during additive manufacturing, leading to functional properties and poor mechanical properties. The printer head modification is carried out to print the novel natural fiber granulated composites (NFGCs) to overcome these limitations. The objective of the work is to design and develop the 3D printer for the hybrid additive manufacturing technique (HAMT) by combining the fused deposited modeling (FDM) machine with shape deposition modeling (SDM). NFGC materials are developed using the HAMT method, and the influence of the number of layers on the mechanical properties of such as tensile, flexural, impact strength, and hardness of the material is experimentally investigated. The prepared samples are tested on mechanical properties as per the ASTM standards. Furthermore, the filler distribution characteristics of the prepared sample are examined using SEM analysis. 


\section{Machine Design}

The Prusa i3 3D printer is shown in Figure 1(a) with a printer head. The machine's printing head alone is modified and designed to print the composite material paste. The heater in the FDM variant 3D printer is used to melt and extrude the filament, whereas SDM prints less dense materials like food paste, jelly material, and human cell. The material which is synthesized for the work is harder than the material used in SDM. The present work focuses on adopting both techniques to form a HAMT. A better efficient printer head is required to print this material, so the physical iteration process is carried out. The first iteration from the printer with head modification is shown in Figure 1(b). This modification has disadvantages such as the inability to print smoothly, and the motor mounted vertically in line with the syringe leads to vibration and is unable to distribute the load properly, so the second modification is made, as shown in Figure 1(c). This is the final modified printing head, which leads to the development of a HAMT. Figure 2 represents a detailed view of the final modified printer. The printer head modification is done with the same motor as used in the first iteration, but during the second iteration, the printer's efficiency increased. The disadvantages stated in the first iteration are rectified in the second version. The technical specification of the machine is tabulated in Table 1.

2.1. Materials and Methods. The natural fiber granulated composite material has been manufactured using a hybrid additive manufacturing technique in this work. The material was prepared using the fibers from sugarcane, jute, ramie, banana, pineapple fibers, and in addition, the seashell powder was added.

The fibers were washed with distilled water to remove their impurities. At the ambient conditions, it was dried for twenty-four hours, and further, it was treated with a 5\% $\mathrm{NaOH}$ solution at room temperature for another three hours. A hot oven was used to heat the fibers and dehydrate them at $80^{\circ} \mathrm{C}$ for 3 hours. The interface strength and mechanical properties of NFGC were improved by treating the fiber using alkaline treatment $[12,13]$. Further, these materials were powdered in the ball mill with its size ranging from 70 to $100 \mu \mathrm{m}$.

2.2. Preparation of Composite. The sugarcane fiber can be ground thoroughly and powered quickly. It possesses good mixing capability and has excellent torsion rigidity [32]. Jute and ramie fibers are hard to grind. Still, they possess an excellent tensile strength of around $80 \mathrm{MPa}$ [33], possess better cohesive strength, and bind all the materials together with higher compressibility [34]. Pineapple fiber is not easy to grind but possesses the highest tensile strength [35]. Banana fiber possesses smaller elongation even though it cannot be easily powered [36]. The materials mentioned above are ground and sieved using a very fine mesh. Jute, ramie, and pineapple are fluffy, and this fluffiness is reduced comparatively by adding sea shell powder. The mixture has to be converted into paste form; all the powders are mixed well with Araldite (2011A/B epoxy adhesive) and hardener (Aradur 115BD hardener) to make a fine paste. The binders (Araldite and hardener) act as reinforcement agents, which enhance the strength. To increase the wear resistance on both sides, glass fiber is attached after printing the composite material on both sides. The fibers and their powdered form are shown in Figure 3. The individual composition fiber and its properties are shown in Figure 4. The material composition consists of $80 \%$ of powdered fiber and $20 \%$ of binder. Once the required material is prepared, then the NFGC material is printed with a novel printing header help.

The hybrid additive manufacturing works in the following way: FDM is adopted to supply heat input through the base plate and the slicing technique. The maximum heat supplied is around $60^{\circ} \mathrm{C}$, and SDM is used for simple deposition as per layer thickness. In this printer head, a motor is used to print the high-density material for the proper dispensing. So the hybridization provides a clear way to print the composite material. The dimension of the printed NFGC is $250 \times 125 \times 13 \mathrm{~mm}^{3}$, and it is shown in Figure 5 . The material flows through the nozzle and the feed rate is suitably adjusted for varying the layers during printing. Layer orientation is fixed to $0^{\circ}$, and a varying number of layers of NFGC materials are divided into $6,8,10$, and 12 equal parts along with their thickness. The thickness of the material printed during the composite manufacturing process is shown in Table 2.

2.3. Mechanical Testing. The mechanical properties of NFGC material are analyzed by using tensile, flexural, impact, and hardness using the test standards provided by ASTM D638 [40], ASTM D790 [41], ASTM D256 [42], and ASTM D2240 [43] standards, respectively. The test specimens have been made for the tensile test as shown in Figure 6(a) with a length, width, and thickness of $240 \mathrm{~mm}, 20 \mathrm{~mm}$, and $13 \mathrm{~mm}$, respectively. The test has been carried out in the universal testing machine, and the tensile stress is developed by towing the members apart in the opposite direction. The tensile test has been carried for all four variants of a number of layers, with five tests for each case. Therefore, 20 total numbers of specimens are tested, and the best three average values in each case are considered for analyzing the behavior of the material.

The flexural test was also carried out for all four variants of a number of layers with five tests for each case, and the specimen dimensions are shown in Figure 6(b) with a length, width, and thickness of $160 \mathrm{~mm}, 20 \mathrm{~mm}$, and $13 \mathrm{~mm}$, respectively. During the test, the specimens are subjected to both tensile and compressive forces, and the best three average values in each case are considered for evaluating the flexural strength. The specimen for impact test and hardness has been prepared with a length of $160 \mathrm{~mm}$, a width of $20 \mathrm{~mm}$, and thickness of $13 \mathrm{~mm}$ as shown in Figures 6(c) and 6(d), respectively.

Fourier transform infrared (FTIR) spectrometer is a valuable analytical instrument for analyzing hydrogen bond differences due to different defects and structural determination of functional groups and compounds. It is also used 


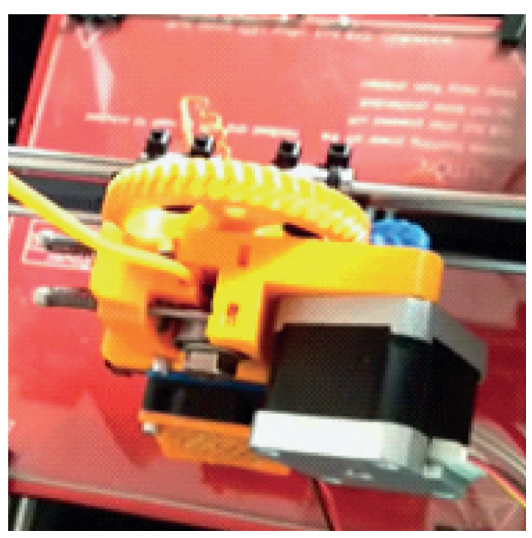

(a)

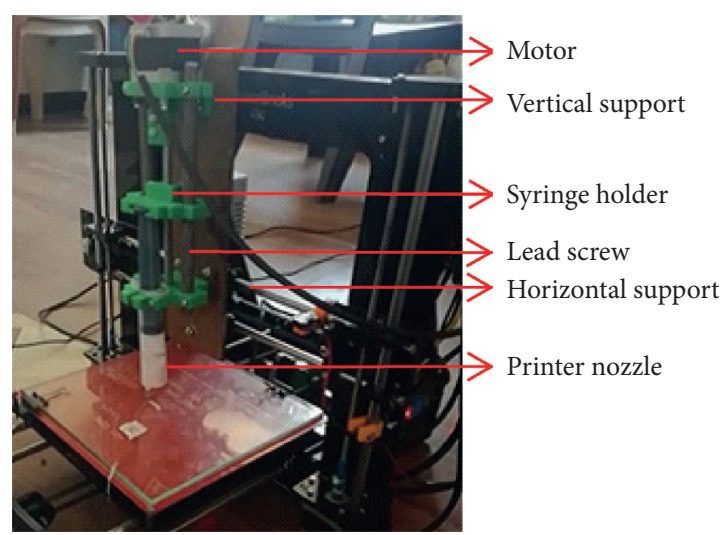

(b)

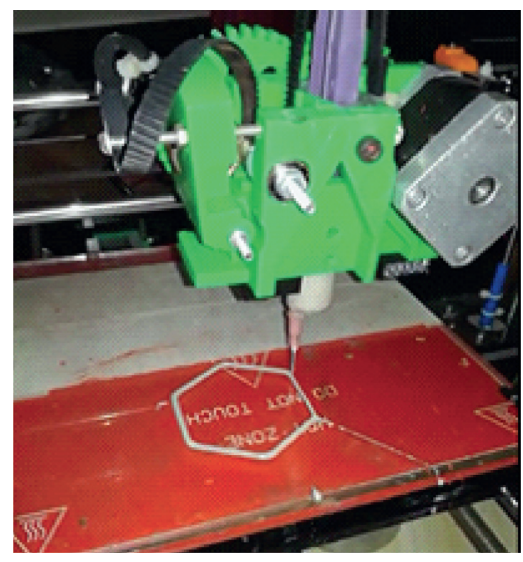

(c)

FIGURE 1: (a) 3D printer with FDM printing head; (b) first iterated printing head; (c) second iterated printing head.

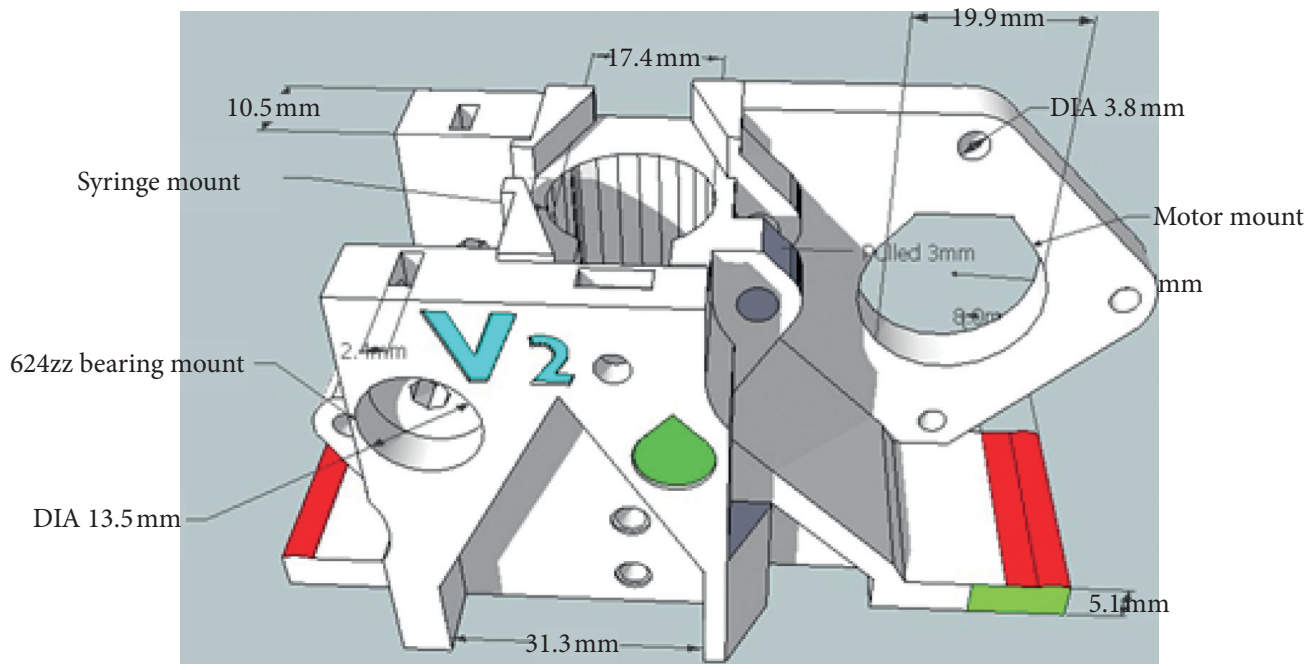

Paste extruder syringe mount

FIGURE 2: Isometric view of $3 \mathrm{D}$ printing head.

to examine the bonding behavior of natural fiber composites [37]. Cellulose, hemicellulose, and lignin are the primary constitutions of natural fibers, while waxes, water-soluble, pectin, and mineral elements are the minor constituents. In general, FTIR has been used to examine natural fibers with different chemical treatments such as alkaline, silane, 
TABLE 1: Technical specification of hybrid additive manufacturing machine.

\begin{tabular}{lr}
\hline Parameters & Specification \\
\hline Build volume & $30 \times 18 \times 18 \mathrm{~cm}$ \\
Layer weight & $0.05-2 \mathrm{~mm}$ \\
Maximum travel speed & $200 \mathrm{~mm} / \mathrm{s}$ \\
Maximum hot end/heat bed temperature & $250^{\circ} \mathrm{C} / 80^{\circ} \mathrm{C}$ \\
\hline
\end{tabular}

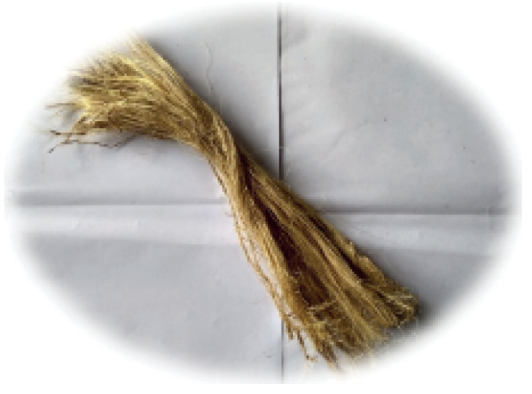

(a)

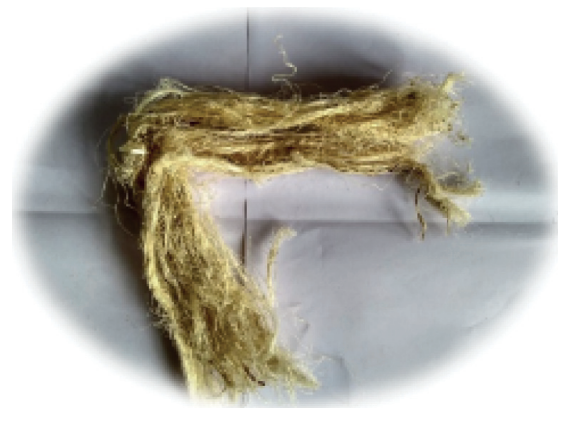

(d)

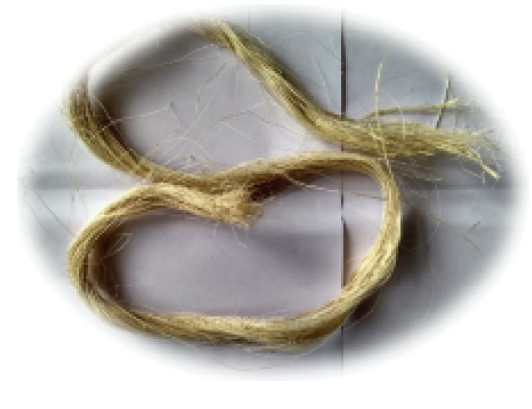

(b)

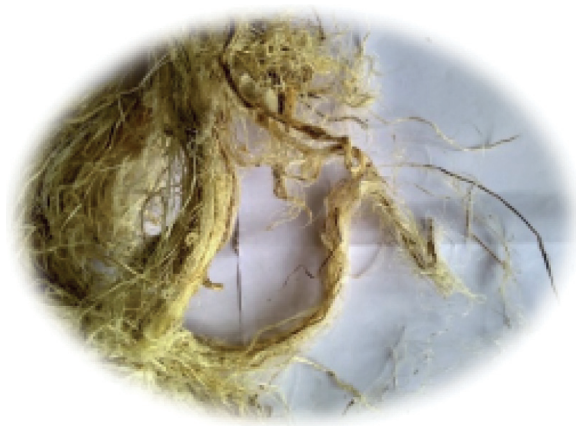

(e)

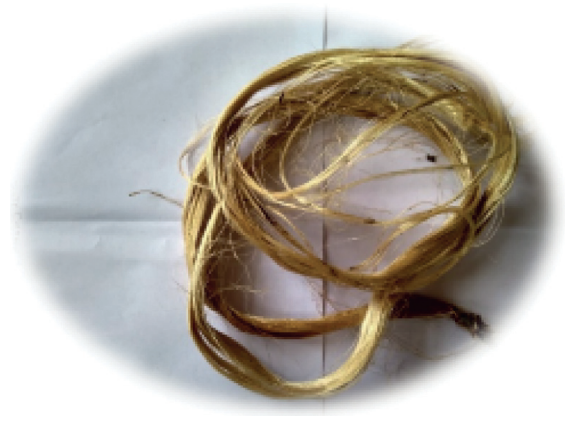

(c)

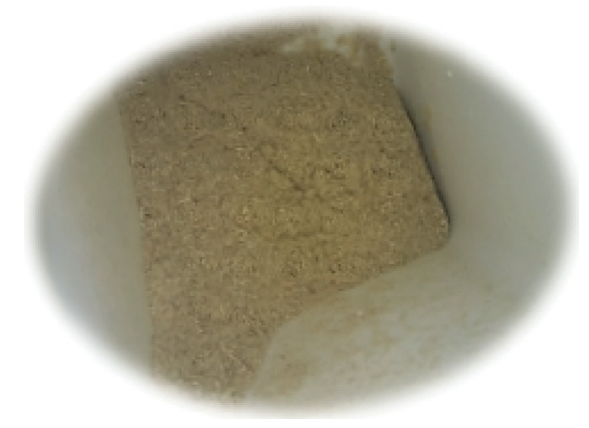

(f)

Figure 3: Various fibers used in NFGCs. (a) Sugarcane fiber. (b) Banana fiber. (c) Jute fiber. (d) Banana fiber. (e) Ramie fiber. (f) Powdered fiber.

peroxide, acetylation, and maleated anhydride with FTIR researchers help able to acquire much more in-depth information about natural fibers after various modifications.

\section{Results and Discussions}

The influence of several layers on the mechanical properties of natural fiber granulated composite made up of HAMT is evaluated by using tensile, flexure, impact, and hardness tests. Further, the use of FTIR and SEM images of the specimen and the prepared material mechanical properties are discussed in the following sections.

3.1. Tensile Strength. The effect of the number of layers on the tensile strength of an NFGC is carried out by the following standard ASTM D638. The results are shown in Figure 7. The test for the specimens has been carried out at the speed of $2 \mathrm{~mm} / \mathrm{min}$. The tensile strength is determined by using the following relationship:

$$
\sigma_{t}=\frac{F}{b \times d}
$$

where $\mathrm{F}, b$, and $d$ represent the applied load, breadth, and thickness of the workpiece, respectively.

From the figure, it is observed that the tensile strength of the NFGC material increases with an increase in the number of layers. The maximum average value of tensile strength of $30.15 \mathrm{MPa}$ has been observed when the number of layers in the material is equal to 12 . The tensile strength of 12-layer specimens has been enhanced by $40.84 \%, 24.67 \%$, and $5.8 \%$ as compared with 6-, 8-, and 10-layer samples, respectively. This is due to the fact that increasing the number of layers reduces the layer thickness and improvement in the interlayer bonding strength by avoiding the formulation of larger-sized microvoids. The rise in the number of layers also progresses the reinforced strength and uniformly improves the load distribution.

Table 3 compares the tensile strength described in the present study with the previous work carried out by Palani Kumar et al. [44] and Ku Harry et al. [45]. The comparison 


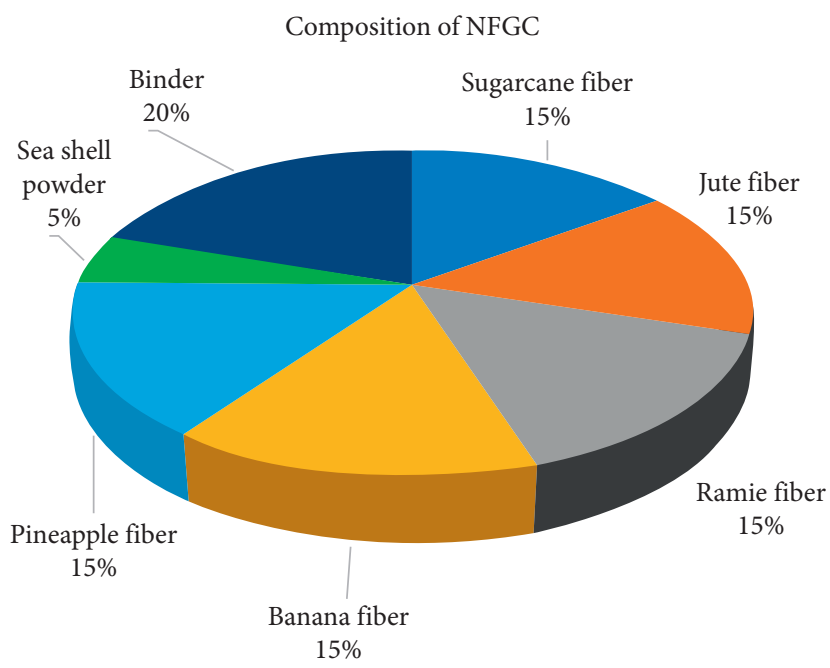

Figure 4: Composition of fibers in NFGCs.

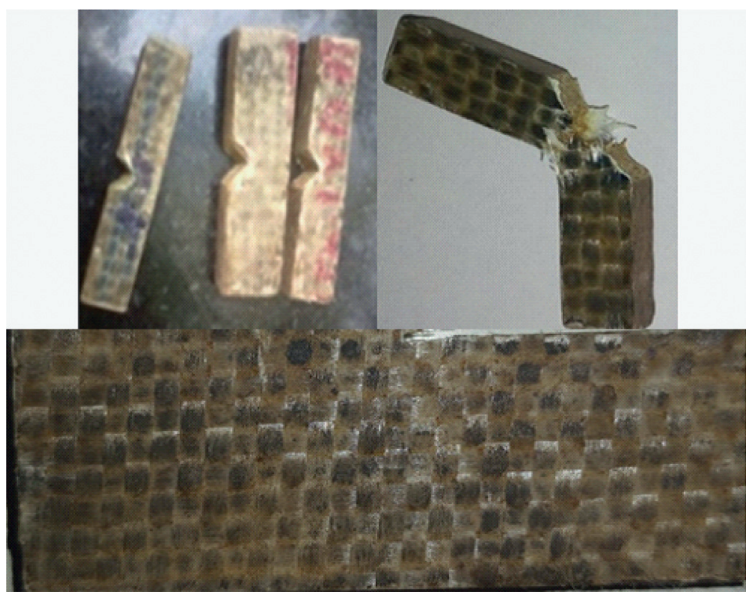

Figure 5: Printed NFGC by using HAMT.

TABLE 2: Printing thickness variations.

\begin{tabular}{lcc}
\hline Number of layers & Total thickness $(\mathrm{mm})$ & Thickness of each layer $(\mathrm{mm})$ \\
\hline 6 & 13 & 2.16 \\
8 & 13 & 1.62 \\
10 & 13 & 1.3 \\
12 & 13 & 1.08 \\
\hline
\end{tabular}

results concluded that the developed material enhances the tensile properties by $1.8,1.37,1.67$, and 2.01 times compared with coconut fiber, 20-mesh hardwood, 40-mesh hardwood, and rice hull fiber composites, respectively.

3.2. Flexural Strength. Figure 8 illustrates the flexural strength of the NFGC material which has been measured by adhering to the standard of ASTM D790. The figure shows that the workpiece sample with maximum layers has resulted in the maximum average flexural strength. The flexural strength of the workpiece has been evaluated by using the following equation:

$$
\sigma_{f}=\frac{3 p l}{2 b d^{2}}
$$

where $p$ and $l$ represent the applied pending load and span length of the workpiece, respectively.

The increased number of layers of the laminate improved the flexural strength. This may be due to the large use of fibers with the layer formation. The average flexural strength of the specimen is found as 50.04, 53.46, 56.74, and 


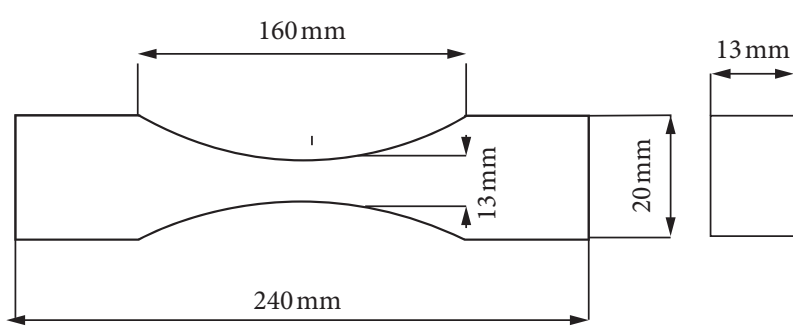

(a)

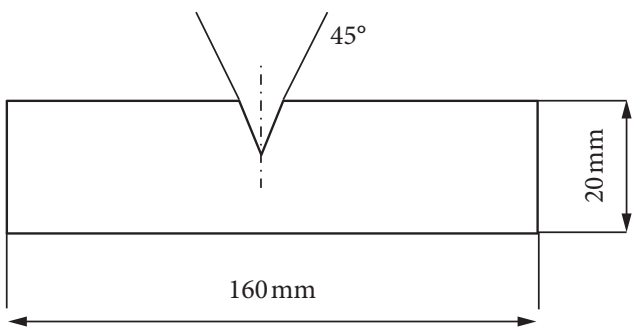

(c)
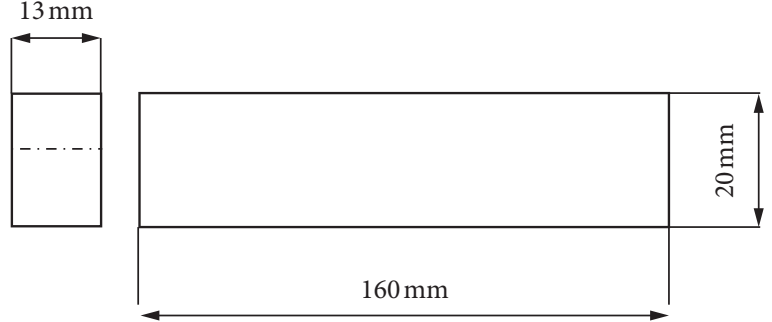

(d)

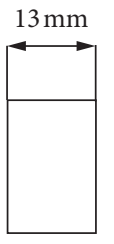

Figure 6: Test specimen for tensile, flexural, impact, and hardness test.

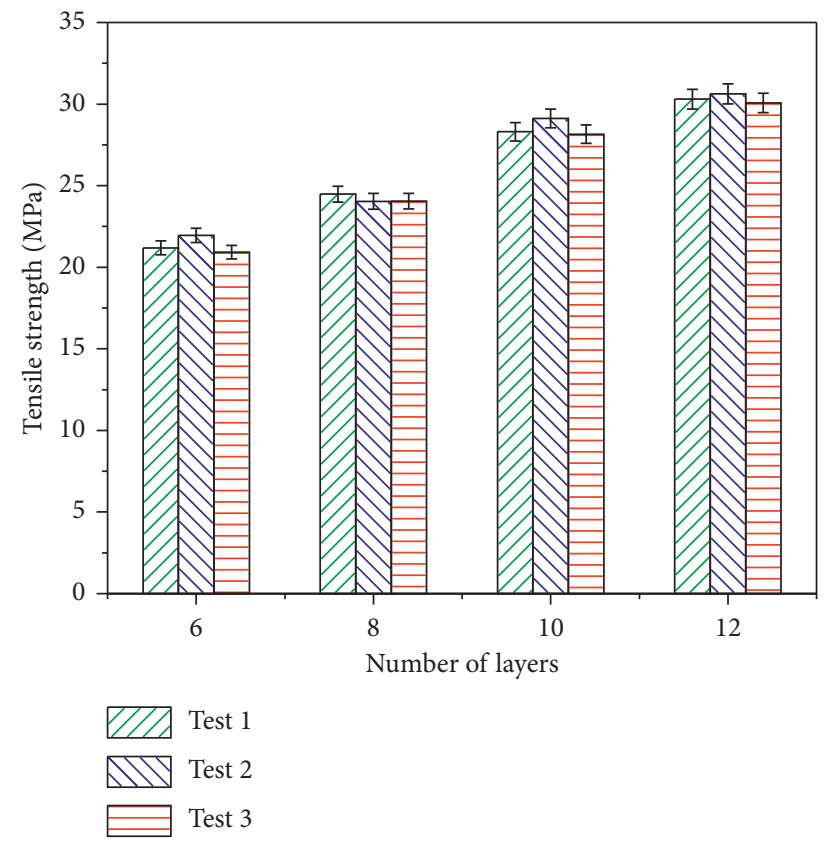

Figure 7: Influence of the number of layers on tensile strength.

TABLE 3: Comparison based on the tensile properties.

\begin{tabular}{lccc}
\hline Fiber & Composition & Tensile strength (MPa) & References \\
\hline Sugarcane, jute, ramie, banana, and pineapple fiber & $80 \%$ fiber $+20 \%$ binder & 30.15 & Present work \\
Coconut fiber & $60 \%$ fiber $+40 \%$ resin & 16.72 & Palani Kumar et al. [42] \\
20-mesh hard wood & $35 \%$ fiber $+65 \%$ resin & 22 & Ku, harry et al. [43] \\
40-mesh hard wood & $35 \%$ fiber $+65 \%$ resin & 18 & 15 \\
Rice hull fiber & $35 \%$ fiber $+65 \%$ resin & & \\
\hline
\end{tabular}

60.83 MPa for 6-, 8-, 10-, and 12-layer specimens, respectively. The lower flexural strength may also due to the effect of adhesive strength. The flexural strength of 12-layer specimens is enhanced by $21.55 \%, 13.79 \%$, and $6.73 \%$ as compared with 6-, 8-, and 10-layer samples, respectively. This phenomenon occurs due to the lower thickness of the 

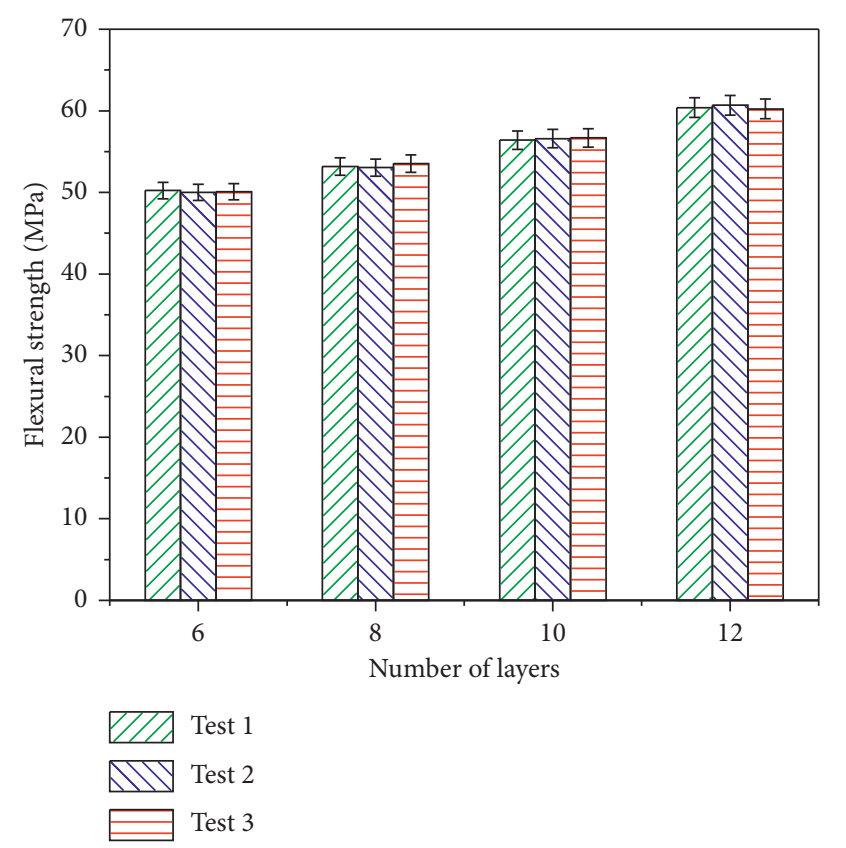

FIGURE 8: Influence of the number of layers on flexural strength.

printed specimen, which decreases the porosity along its cross section compared with greater thickness values of NFGC specimens. Also, the natural fibers enhance the interfacial bonding with the surface for improved structural behavior. The stronger interfacial bonds greatly influence the flexural strength which may also be a cause for improved flexural strength. Furthermore, the lower thickness composites minimize the stress concentration points between the layers, and with better curing, the flexural properties are improved.

3.3. Impact Strength. The influence of a number of layers on the impact strength of an NFGC is carried out by following standard ASTM D256, and the results are plotted in Figure 9. The notch has been formulated in the test specimens in such a way that the deformation is avoided which is caused during the impact force. The average impact strength values for the specimen are $24.71,28.62,31.78$, and $37.43 \mathrm{MPa}$ for 6-, 8-, 10-, and 12-layer NFGC specimens, respectively. From the results, it is clear that the 12-layer specimen improves the impact strength by $21.55 \%, 13.79 \%$, and $6.73 \%$ compared with 6-, 8-, and 10-layer samples, respectively. This happens because when increasing the number of layers, the fiber layer fineness improves and enhances the absorbed energy during the test. Furthermore, ramie and banana fiber presence enhances the cohesive forces, leading to agglomeration between the molecules.

3.4. Hardness. Figure 10 plots the hardness of the NFGC material with different layers. The figure shows that the workpiece sample with maximum layers has resulted in the maximum average value of hardness. It is observed that the hardness value of the composite increases with an increase in the laminate layer. The specimen average hardness values are
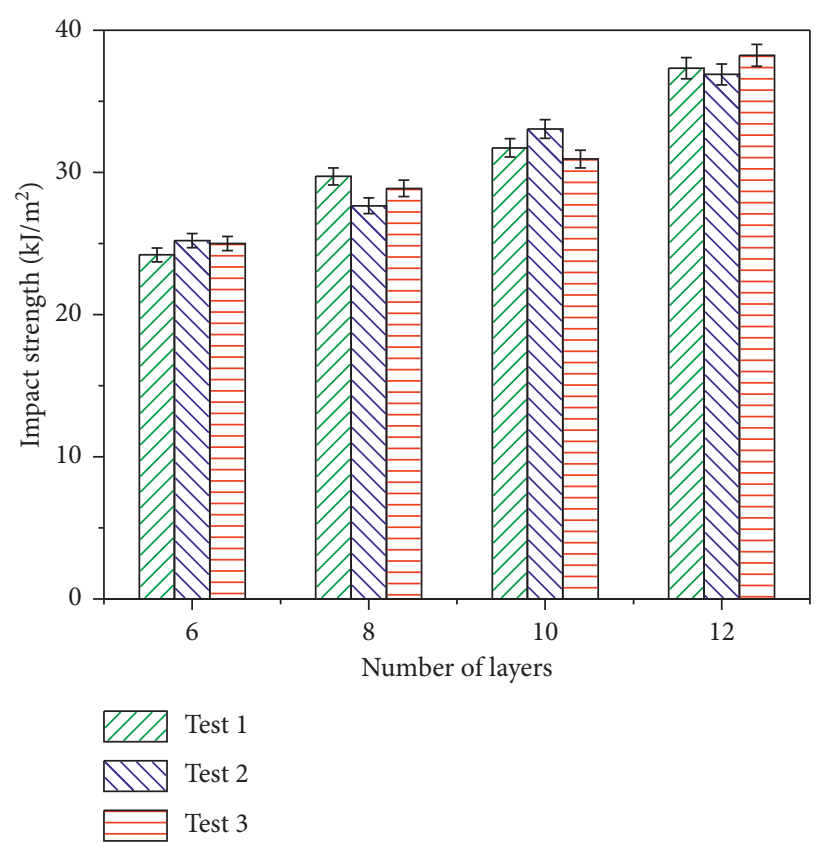

Figure 9: Influence of the number of layers on impact strength.

78.33, 81.66, 89, and 94.33 Shore D for 6-, 8-, 10-, and 12-layer specimens, respectively. The stronger interface bonding of the natural fiber with the composite improved the hardness. The results show that the provision of a more significant number of layers for the same thickness enhances the hardness value with better penetration between the successive layers. Further, it also minimizes the anisotropy nature of the composite which significantly improves the hardness value.

3.5. Fourier Transform Infrared (FTIR) Spectrometry. The natural fiber spectrum functional groups are detected by using FTIR in the range of 500 to $4000 \mathrm{~cm}^{-1}$, as shown in Figure 11. The FTIR spectrum clearly shows the functional groups of cellulose, hemicellulose, and lignin. The bands observed at $1764 \mathrm{~cm}^{-1}$ and $1678 \mathrm{~cm}^{-1}$ are $-\mathrm{C}=O$ stretching vibration and bending vibrations in the alphake to carboxylic acid in lignin and acetyl groups in hemicellulose, respectively. The distinct peak at $1446 \mathrm{~cm}^{-1}$ is assigned to the cellulose $\mathrm{CH}_{2}$ bending vibration. The existence of wax is observed through a peak at $2410 \mathrm{~cm}^{-1}$. The sharp peak at $2940 \mathrm{~cm}^{-1}$ is attributed to the $\mathrm{C}-\mathrm{H}$ stretching of cellulose existing in fiber. The bands observed at 2940 and $2324 \mathrm{~cm}^{-1}$ are the stretching vibration of the $\mathrm{C}-\mathrm{H}$ and $\mathrm{CH}_{2}$ bonds present in aromatic rings of hemicellulose and cellulose. Removal of hemicelluloses can also cause reduced shear stress transfer under tensile loading and loss of lignin. The peak at $3054 \mathrm{~cm}^{-1}$ is attributed to $\mathrm{C}-\mathrm{H}$ stretching vibration which may be caused by the existence of higher cellulose. The FTIR study shows that alkaline treatment eliminated much of lignin and hemicellulose contents on the fibers, which helped enhance the composite mechanical properties. It is also found that an increase in $\mathrm{NaOH}$ concentration above $5 \%$ 


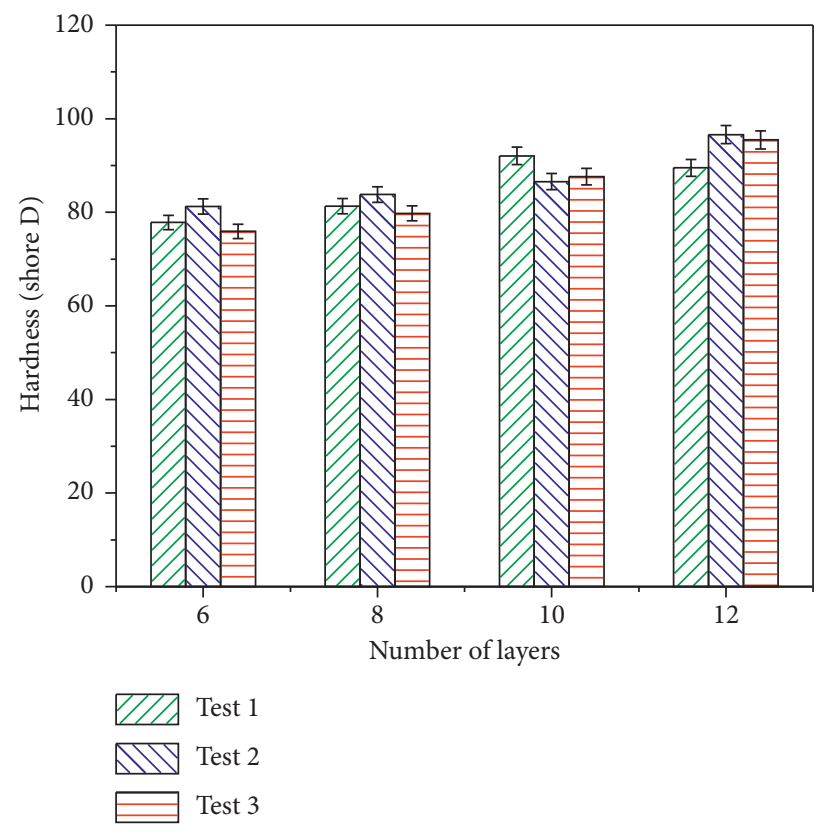

Figure 10: Influence of the number of layers on hardness.

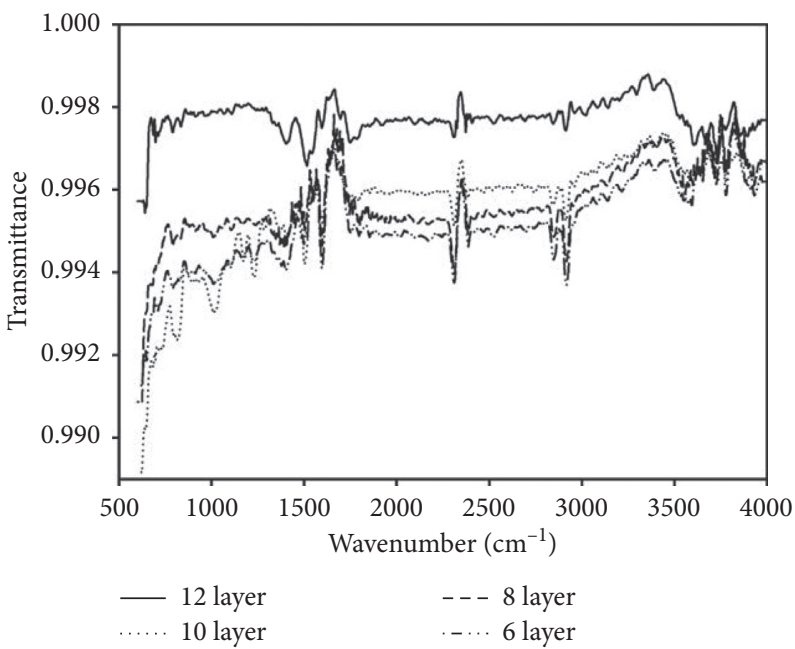

FIGURE 11: FTIR result for impact test specimens.

damaged the fiber surface, resulting in weak adhesion between fiber and matrix that decreases the mechanical properties of composites.

3.6. SEM Analysis. The SEM test has been carried out for evaluating the molecular interactions of NFGC materials made up of various layer thicknesses. The test has been conducted using scanning electron microscopy with focusing distance and working voltage of 9.8 to $12.1 \mathrm{~mm}$ and $20 \mathrm{kV}$, respectively. The micrographic SEM images for 6-, 8-, 10-, and 12-layer fractured test specimens from the impact test are shown in Figures 12(a)-12(d), respectively.
With the addition of fibers with resin and increased laminate structure, the mechanical properties significantly change which is directly influenced with the void formation. By comparing the figures, it is evidenced that the 12-layer specimens have a lower amount of void formulation. There were several factors that influence the void formation: (i) entrapment of air during the mixing process, (ii) moisture vaporization by the surfaces of the substrate, and (iii) preparation technique for substrate surface. It is clear that the laminate with an increased number of layers and reduced printing thickness improved the mechanical properties, which makes the uniform distribution of material and reduces void 


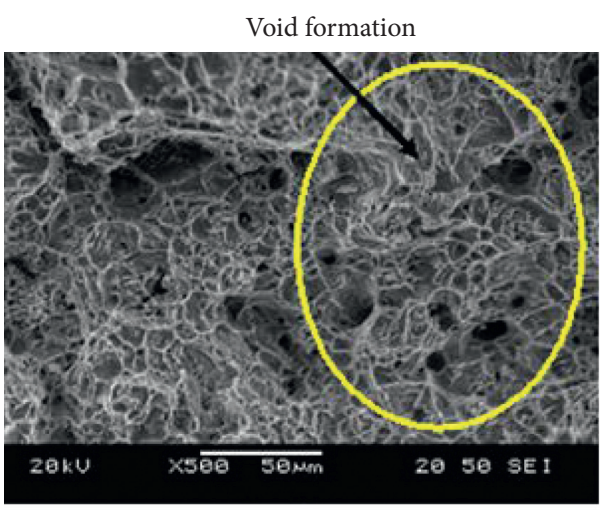

(a)

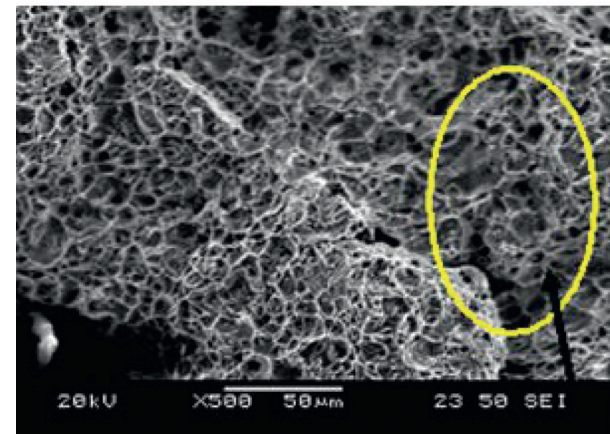

(c)

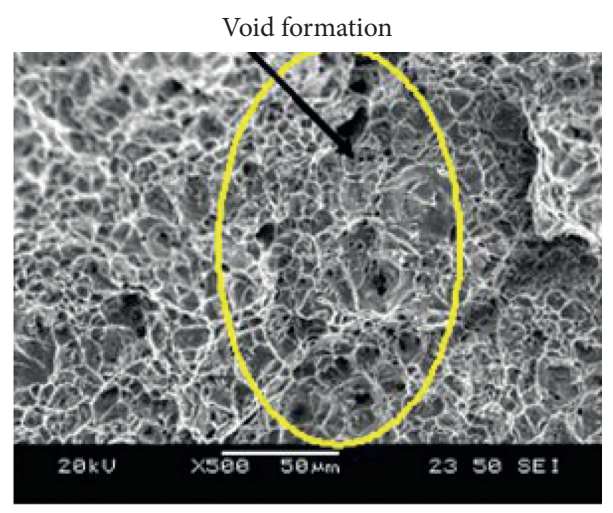

(b)

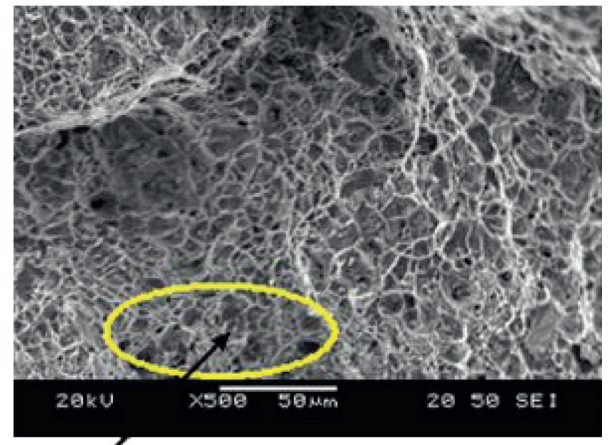

(d)

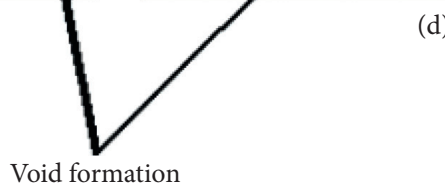

Figure 12: SEM result for (a) 6-layer, (b) 8-layer, (c) 10-layer, and (d) 12-layer impact test specimen.

formation. On the other hand, due to poor interlaminar bonding, the lower layered specimen developed porous holes and voids.

\section{Conclusion}

The natural fiber granulated composite is an effective alternative approach to produce the material for engineering application without compromising its quality. Further, it can be utilized for biomedical, automotive, packing, and constructional applications. The material grinding and binding methodology can be improved by analyzing various combinations of fibers. The HAMT method could open up many new components because of the multiple material development, leading to a new paradigm shift in the material industry and manufacturing composite materials. The HAMT method shows that sublayers with multiple materials can be developed. The following conclusions are drawn from the novel approach of printer modification and composite material preparation: [38], [39], [51], [52], [53]

The experimental results show that increasing the number of layers enhances the mechanical properties due to the better bonding between the successive layers. The tensile flexural, impact, and hardness values are enhanced by $40.84,50.04,21.55$, and
$20.55 \%$ when increasing the number of layers from 6 to 12 .

The enhancement in mechanical properties is due to adhesion at the interface caused by chemical treatment and is evidenced with FTIR analysis.

SEM test obviously describes reducing void content by increasing the number of layers into the NFGC.

\section{Data Availability}

The data used to support the findings of this study are available from the corresponding author upon request.

\section{Conflicts of Interest}

The authors declare that they have no conflicts of interest.

\section{References}

[1] M. Ramesh, K. Palanikumar, and K. H. Reddy, "Plant fibre based bio-composites: sustainable and renewable green materials," Renewable and Sustainable Energy Reviews, vol. 79, pp. 558-584, 2017.

[2] V. K. Balla, K. H. Kate, J. Satyavolu, P. Singh, and J. G. D. Tadimeti, "Additive manufacturing of natural fiber reinforced polymer composites: processing and prospects," 
Composites Part B: Engineering, vol. 174, Article ID 106956, 2019.

[3] S. V. Joshi, L. T. Drzal, A. K. Mohanty, and S. Arora, "Are natural fiber composites environmentally superior to glass fiber reinforced composites?" Composites Part A: Applied Science and Manufacturing, vol. 35, no. 3, pp. 371-376, 2004.

[4] A. R. Prasad and K. M. Rao, "Mechanical properties of natural fibre reinforced polyester composites: jowar, sisal and bamboo," Materials \& Design, vol. 32, no. 8-9, pp. 4658-4663, 2011.

[5] E. Bodros, I. Pillin, N. Montrelay et al., "Could biopolymers reinforced by randomly scattered flax fibre be used in structural applications," Composites Science and Technology, vol. 67, no. 3-4, pp. 462-470, 2007.

[6] A. Alavudeen, N. Rajini, S. Karthikeyan, M. Thiruchitrambalam, and N. Venkateshwaren, "Mechanical properties of banana/ kenaf fiber-reinforced hybrid polyester composites: effect of woven fabric and random orientation," Materials \& Design (1980-2015), vol. 66, pp. 246-257, 2015.

[7] N. Venkateshwaran, A. ElayaPerumal, A. Alavudeen, and M. Thiruchitrambalam, "Mechanical and water absorption behaviour of banana/sisal reinforced hybrid composites," Materials \& Design, vol. 32, no. 7, pp. 4017-4021, 2011.

[8] L. J. d. Silva, T. H. Panzera, A. L. Christoforo, J. C. C. Rubio, and F. Scarpa, "Micromechanical analysis of hybrid composites reinforced with unidirectional natural fibres, silica microparticles and maleic anhydride," Materials Research, vol. 15, no. 6, pp. 1003-1012, 2012.

[9] T. Gurunathan, S. Mohanty, and S. K. Nayak, "A review of the recent developments in biocomposites based on natural fibres and their application perspectives," Composites Part A: Applied Science and Manufacturing, vol. 77, pp. 1-25, 2015.

[10] M. R. Sanjay, P. Madhu, M. Jawaid, P. Senthamaraikannan, S. Senthil, and S. Pradeep, "Characterization and properties of natural fiber polymer composites: a comprehensive review," Journal of Cleaner Production, vol. 172, pp. 566-581, 2018.

[11] K. P. Mieck, T. Reußmann, and A. Nechwatal, "Natural and man-made cellulose fiber-reinforced composites," Handbook of Engineering Biopolymers, vol. 237266 pages, 2015.

[12] R. Kumar, R. P. Singh, and R. Kataria, "Study on mechanical properties of fabricated hybrid natural fibre polymeric composites," International Journal of Materials and Product Technology, vol. 60, no. 1, pp. 73-91, 2020.

[13] P. Koushki, T. H. Kwok, L. Hof et al., "Reinforcing silicone with hemp fiber for additive manufacturing," Composites Science and Technology, vol. 194, Article ID 108139, 2020.

[14] S. Sathish, K. Kumaresan, L. Prabhu, and N. Vigneshkumar, "Experimental investigation on volume fraction of mechanical and physical properties of flax and bamboo fibers reinforced hybrid epoxy composites," Polymers and Polymer Composites, vol. 25, no. 3, pp. 229-236, 2017.

[15] P. Koushki, T. H. Kwok, L. Hof et al., "Reinforcing silicone with hemp fiber for additive manufacturing," Composites Science and Technology, vol. 194, Article ID 108139, 2020.

[16] S. Sathish, K. Kumaresan, L. Prabhu, and N. Vigneshkumar, "Experimental investigation on volume fraction of mechanical and physical properties of flax and bamboo fibers reinforced hybrid epoxy composites," Polymers and Polymer Composites, vol. 25, no. 3, pp. 229-236, 2017.

[17] J.-P. Kruth, M. C. Leu, and T. Nakagawa, "Progress in additive manufacturing and rapid prototyping," CIRP Annals, vol. 47, no. 2, pp. 525-540, 1998.

[18] A. Goyanes, M. Kobayashi, R. Martínez-Pacheco, S. Gaisford, and A. W. Basit, "Fused-filament 3D printing of drug products: microstructure analysis and drug release characteristics of PVA-based caplets," International Journal of Pharmaceutics, vol. 514, no. 1, pp. 290-295, 2016.

[19] R. Matsuzaki, M. Ueda, M. Namiki et al., "Three-dimensional printing of continuous-fiber composites by in-nozzle impregnation," Scientific Reports-UK, vol. 11, p. 6, Article ID 23058, 2016.

[20] S. A. Hinchcliffe, K. M. Hess, and W. V. Srubar III, "Experimental and theoretical investigation of prestressed natural fiber-reinforced polylactic acid (PLA) composite materials," Composites Part B: Engineering, vol. 95, pp. 346-354, 2016.

[21] A. Le Duigou, M. Castro, R. Bevan, and N. Martin, "3D printing of wood fibre biocomposites: from mechanical to actuation functionality," Materials \& Design, vol. 96, pp. 106-114, 2016.

[22] L. Duigou, D. C. Antoine, M. Ueda, R. Matsuzaki, and M. Castro, "A review of 3D and 4D printing of natural fibre bio composites," Materials \& Design, Article ID 108911, 2020.

[23] D. O’Connor, TCT Magazine, 10 New Materials You Can Now Print with, Luis Pascoa Publications, Stuttgart, Germany, 2014.

[24] D. O'Connor, TCT Magazine, Graphene 3D Lab to Launch Water-Soluble 3D Printing Filament, Springer, Berlin, Germany, 2015.

[25] D. O'Connor, TCT Magazine, The Virtuous Circle of AlgaeInfused PLA by Algix and 3D Fuel, Springer, Berlin, Germany, 2015.

[26] D. O'Connor, TCT Magazine, Dutch Startup to Bring Aerospace Grade 3D Printing Materials to the Desktop, Research Gate, Berlin, Germany, 2015.

[27] A. Dudal, TCT Magazine, Taking 3D Printing Filament to the Next Level, Research Gate, Berlin, Germany, 2015.

[28] W. Wang, H. Rodrigue, and S. H. Ahn, "Deployable soft composite structures," Scientific Reports-UK, vol. 6, no. 1, pp. 1-0, 2016.

[29] 3DomFuel's, TCTM, 3D Printing Filament Manufacturers Join Forces on New Company 3DomFuel, 3DomFuel's, Fargo, ND, USA, 2016.

[30] FiberLab, TCTM, FIBERLAB Releases Flexible and Temperature Fluctuation Resistant Fiber Flex 40D 3D Printing Filament, FiberLab, Naples, Italy, 2017.

[31] D. Isakov, C. J. Stevens, F. Castles et al., "A split ring resonator dielectric probe for near-field dielectric imaging," Scientific Reports-UK, vol. 7, no. 1, pp. 1-9, 2017.

[32] R. Matsuzaki, M. Ueda, M. Namiki et al., "Three-dimensional printing of continuous-fiber composites by in-nozzle impregnation," Scientific Reports-UK, vol. 6, Article ID 23058, 2016.

[33] D. Owen, J. Hickey, A. Cusson, O. I. Ayeni et al., "3D printing of ceramic components using a customized 3D ceramic printer," Progress in Additive Manufacturing, vol. 3, no. 1-2, pp. 3-9, 2018.

[34] S. D. Asagekar and V. K. Joshi, "Characteristics of sugarcane fibres Indian," Indian Journal of Fibre \& Textile Research, pp. 180-184, 2014.

[35] S. Arunavathi, R. D. Eithiraj, and K. Veluraja, "Physical and mechanical properties of jute fiber and jute fiber reinforced paper bag with tamarind seed gum as a binder-An eco-friendly material," in AIP Conference Proceedingsvol. 1832, no. 1, AIP Publishing LLC, Article ID 040026, 2017.

[36] C. Xu, Y. Gu, Z. Yang, M. Li, Y. Li, and Z. Zhang, "Mechanical properties of surface-treated ramie fiber fabric/epoxy resin composite fabricated by vacuum-assisted resin infusion 
molding with hot compaction," Journal of Composite Materials, vol. 50, no. 9, pp. 1189-1198, 2016.

[37] M. Asim, K. Abdan, M. Jawaid et al., "A review on pineapple leaves fibre and its composites," International Journal of Polymer Science, vol. 201516 pages, 2015.

[38] R. Bhatnagar, G. Gupta, and S. Yadav, "A review on composition and properties of banana fibers," International Journal of Scientific and Engineering, vol. 6, no. 5, pp. 49-52, 2015.

[39] J. C. Río Andrade, A. Gutiérrez Suárez, R. García et al., "Composition of non-woody plant lignins and cinnamic acids by Py-GC/MS, Py/TMAH and FT-IR,” Journal of Analytical and Applied Pyrolysis, vol. 791, pp. 39-46, 2007.

[40] ASTM D638-14, Standard Test Method for Tensile Properties of Plastics, ASTM International, West Conshohocken, PA, USA, 2014.

[41] ASTM D790-17, Standard Test Methods for Flexural Properties of Unreinforced and Reinforced Plastics and Electrical Insulating Materials, ASTM International, West Conshohocken, PA, USA, 2017.

[42] ASTM D256-10 (2018), Standard Test Methods for Determining the Izod Pendulum Impact Resistance of Plastics, ASTM International, West Conshohocken, PA, USA, 2018.

[43] ASTM D2240-15e1, Standard Test Method for Rubber Property-Durometer Hardness, ASTM International, West Conshohocken, PA, USA, 2015.

[44] K. Palani Kumar, D. Keshavan, E. Natarajan et al., "Evaluation of mechanical properties of coconut flower cover fibrereinforced polymer composites for industrial applications," Progress in Rubber, Plastics and Recycling Technology, vol. 37, no. 1, pp. 3-18, Article ID 1477760619895011, 2020.

[45] H. Ku, H. Wang, N. Pattarachaiyakoop, and M. Trada, "A review on the tensile properties of natural fiber reinforced polymer composites," Composites Part B: Engineering, vol. 42, no. 4, pp. 856-873, 2011.

[46] R. S. Kumar, N. Muralidharan, and R. Sathyamurthy, "Optimization of alkali treatment process parameters for kenaf fiber: experiments design," Journal of Natural Fibers, vol. 202010 pages, 2020 .

[47] S. D. Malingam, L. F. Ng, K. H. Chan, K. Subramaniam, M. Z. Selamat, and K. A. Zakaria, "The static and dynamic mechanical properties of kenaf/glass fibre reinforced hybrid composites," Materials Research Express, vol. 5, no. 9, Article ID 095304, 2018.

[48] T. Merizgui, A. Hadjadj, M. Kious, V. A. Prakash, and B. Gaoui, "Effect of magnetic iron (III) oxide particle addition with MWCNTs in kenaf fibre-reinforced epoxy composite shielding material in "E", "F", "I" and "J" band microwave frequencies," Materials Research Express, vol. 6, no. 4, Article ID 046102, 2019.

[49] M. Nematollahi, M. Karevan, P. Mosaddegh, and M. Farzin, "Morphology, thermal and mechanical properties of extruded injection molded kenaf fiber reinforced polypropylene composites," Materials Research Express, vol. 6, no. 9, Article ID 095409, 2019.

[50] S. S. Abhilash and D. L. Singaravelu, "Effect of fiber content on mechanical and morphological properties of bamboo fiber-reinforced linear low-density polyethylene processed by rotational molding," Transactions of the Indian Institute of Metals, vol. 20206 pages, 2020.

[51] R. Vijay, A. Vinod, R. Kathiravan, S. Siengchin, and D. L. Singaravelu, "Evaluation of Azadirachta indica seed/ spent Camellia sinensis bio-filler based jute fabrics-epoxy composites: experimental and numerical studies," Journal of Industrial Textiles, vol. 49, no. 9, pp. 1252-1277, 2020.

[52] S. Dinesh, P. Kumaran, S. Mohanamurugan et al., "Influence of wood dust fillers on the mechanical, thermal, water absorption and biodegradation characteristics of jute fiber epoxy composites," Journal of Polymer Research, vol. 27, no. 1, pp. 1-13, 2020.

[53] S. Jothibasu, S. Mohanamurugan, R. Vijay, D. Lenin Singaravelu, A. Vinod, and M. Sanjay, "Investigation on the mechanical behavior of areca sheath fibers/jute fibers/glass fabrics reinforced hybrid composite for light weight applications," Journal of Industrial Textiles, vol. 49, no. 8, pp. 1036-1060, 2020. 